\title{
Preferences and Positivist Methodology in Economics
}

\author{
Christopher Clarke*†
}

I distinguish several doctrines that economic methodologists have found attractive, all of which have a positivist flavor. One of these is the doctrine that preference assignments in economics are just shorthand descriptions of agents' choices. Although most of these doctrines are problematic, the latter doctrine about preference assignments is a respectable one, I argue. It does not entail any of the problematic doctrines, and indeed it is warranted independently of them.

1. The Legacy of Positivism in Economics. In the middle decades of the twentieth century, economic methodologists began to advance several doctrines that had a strikingly positivist flavor. This article will examine an organized package of seven such doctrines:

(1) The ultimate, defining aim of the sciences is merely to describe the observable features of the world and to explain these features by reference to other observable features of the world. (2) In fact, the defining aim of economics is merely to explain agents' choices by reference to external constraints such as prices, taxes, technology shocks, and the availability of natural resources. (And by this I mean both the choices made by a single agent

Received November 2014; revised August 2015.

*To contact the author, please write to: Department of History and Philosophy of Science, University of Cambridge; e-mail: cjc84@cam.ac.uk.

$\dagger \mathrm{I}$ am indebted to Anna Alexandrova, Christopher Cowie, and Zina Ward for their invaluable comments on an ancestor of this manuscript, to Ken Binmore and Samir Okasha for many fruitful discussions on the topic, and to several anonymous referees for their helpful comments. This work has received funding from the European Research Council under the European Union's Seventh Framework Programme (FP7/2007-2013)/ERC grant 284123.

Philosophy of Science, 83 (April 2016) pp. 192-212. 0031-8248/2016/8302-0002\$10.00

Copyright 2016 by the Philosophy of Science Association. All rights reserved. 
and the aggregated choices of multiple agents. $)^{1}$ It follows that (3) economic models are just hypotheses about agents' choices given the external circumstances. Admittedly, many economic models appear to describe agents' psychology_including their preferences, expectations, knowledge, and the like. But such models are not to be taken at face value. (4) What is more, hypotheses are only to be tested by their observable implications. So (5) the only evidence that bears on economic models is standard choice data: the choices that agents make and the external circumstances under which they make them. Cognitive and neurobiological data, in contrast, are irrelevant to testing economic models - even if these data show the psychological assumptions behind economic models to be false. Fortunately (6) there is a practical, theory-independent procedure for observing agents' choices. This is what allows economists to test their models and to do so independently of psychological theory. But it turns out that basic economic theory can accommodate the currently available data about agents' choices. So (7) basic economic theory is well confirmed. ${ }^{2}$

This is somewhat of a caricature, and indeed these doctrines are less popular in some quarters of contemporary economics than they once were in the mid-twentieth century (Kahneman, Wakker, and Sarin 1997; Camerer, Loewenstein, and Prelec 2005; Rubinstein and Salant 2008). Nevertheless, some economists today are happy to champion the above package of ideas almost in its entirety (Gul and Pesendorfer 2008).

I follow the majority of philosophers, however, in thinking that many of these positivist ideas are deeply mistaken. I would deny 1 , that the defining aim of the sciences is merely to explain the observable in terms of the observable. I think 2 is overstated. I am happy to think of economics as encompassing many defining aims other than to explain choices by reference to external circumstances. I would also deny 4, that hypotheses are only to be tested by their observable implications, and accordingly I would deny 5 , that only standard choice data bear on economic models. I would also deny 6 , that there is a practical, theory-independent procedure for observing agents' choices. Finally, I have doubts about what the data show, and so I am reluctant to take a position on 7 , the claim that basic economic theory is well confirmed.

Nevertheless, I think that doctrine 3 is defensible: economic models are just hypotheses about agents' choices given the external circumstances. Although many economic models appear to describe agents' preferences,

1. For example, the level of unemployment is an aggregate derived from the choices of workers and firms.

2. See the citations throughout this article at the point that each individual doctrine is discussed. 
expectations, and the like, this is just a convenient shorthand for these choice hypotheses. (This 'shorthand story' about economic models remains an official doctrine of mainstream economics, as codified in some of the leading textbooks in microeconomics and game theory.) ${ }^{3}$

Now, many philosophers reject this shorthand story as a piece of outmoded positivism. I will argue, however, that this critique is unfounded. First, the shorthand story does not issue in any of the problematic positivist doctrines (secs. 3 and 4). And, second, the shorthand story can be warranted entirely independently of them (sec. 5). To put it briefly: the warrant for the shorthand story is to shield economic theory from misguided criticism from psychology. (But this does not entail that it shields economic theory from all criticism from psychology-far from it; see sec. 4).

Thus, the central aim of this article is to present the shorthand story in such a way that it is sharply separated from the other positivist doctrines (sec. 2). This clears the path for an economic methodology that dispenses with these problematic doctrines but retains the shorthand story. Thus far, philosophers have overlooked the possibility of doing this. I recommend this methodology to economists as the best way of doing justice to their desire to shield economic theory from misguided criticism.

I should note some limitations in the ambitions of this article. First, this article defends the shorthand story for the paradigm case of assignments of preferences within economic models. But it leaves aside the wider case of assignments of expectations and knowledge. Second, it focuses on economics as a descriptive science rather than as a normative enterprise, a science of policy or of rationality. Third, limitations of space prevent me from discussing each and every objection to the shorthand story. Most notably, I will not address Sen's (1973) worry with respect to other-regarding agents or Hausman's (2012) argument that appeals to the fact that preferences typically need to combine with beliefs in order to generate action.

Fourth, the main aim of this article is not to critique any of the more problematic positivist doctrines. Fifth, this article does not aim to resolve the controversy over 'idealized assumptions' in economic models: Take the case in which some of a model's content is false - at least at face value. Does this always hinder the aims for which the model is used, or indicate that the model is not fit for purpose. Alternatively, can falsehoods in fact help to further these aims (Friedman 1953; Musgrave 1981; Mäki 2002)? Instead of providing a general answer to such questions, this article speaks to the issue of 'false assumptions' only for the case of preference assignments in economic models. So, of course, my discussion does not apply to those macroeconomic models, for example, that do not assign preferences to agents. Nor does it apply to parts of economic models other than preference assignments.

3. See Varian (1992, 131-33; 2005, 120), Mas-Colell, Winston, and Green (1995, 11), Binmore (2007b, chaps. 1.4.2, 14.1-14.2), and also the citations in sec. 2. 
2. Preference Assignments as a Shorthand. I want to sharply distinguish the shorthand story from the problematic doctrines with which it is often conflated. To this end, this section articulates the shorthand story about preferences in economics in a nonstandard way-in two respects. First, I articulate the shorthand story in terms of the distinction between belief and acceptance, a distinction familiar from general philosophy of science. Second, I exclude any extraneous elements or misleading terminology-especially talk of 'revealed preferences'.

Commonsense Preferences. Standard economic models, when taken at face value, say that agents are maximizers of their preferences - their preferences as understood by commonsense psychology. One can show that this entails the following principle that connects these commonsense preferences and an agent's choices: ${ }^{4}$

(BRIDGE) Take any given agent, Eve for example. If Eve has the following commonsense preferences, then she would make the following choices, and if she would make the following choices, then she has the following commonsense preferences.

Preferences: Eve weakly prefers outcome $x$ to outcome $y$. (I use 'weakly prefers' here in the standard sense to contrast with 'strictly prefers'. $)^{5}$

Choices: In at least one circumstance, Eve would choose to receive outcome $x$ guaranteed, despite the option of receiving outcome $y$ guaranteed also being on the menu.

As an illustration, imagine four circumstances in which Eve might find herself. In the first circumstance she has the choice between lobster and steak; in the second she has the choice between steak and salad; in the third, between lobster and salad; and in the fourth, between all three outcomes. Suppose that, in all four circumstances, Eve would always choose the lobster if it is on the menu; otherwise, she would choose the steak if it is on the menu. If one knew of this pattern of choices, it would be natural to infer that Eve's preferences over these three outcomes are that Eve strictly prefers lobster to steak and steak in turn to salad. Conversely, if one knew these preferences, it would be natural to infer that Eve's choices adhere to the pat-

4. Modulo the assumption that all permutations of outcomes constitute possible menus.

5. To say that Eve weakly prefers $A$ to $B$ is to leave open the possibility that she also weakly prefers $B$ to $A$. Intuitively, it leaves open the possibility that she is indifferent between $A$ and $B$. In contrast, stipulate that Eve strictly prefers $A$ to $B$ if and only if she weakly prefers $A$ to $B$ but not vice versa (Mas-Colell et al. 1995, chap. 1B). 
tern above. And the BRIDGE principle licenses these inferences: it says that Eve has the above commonsense preferences if and only if she would make the above choices in the above circumstances. ${ }^{6}$

To be clear, this talk of circumstances is meant to include circumstances that will never actually materialize. In this sense the above circumstances are 'counterfactual', as are the above choices. (Qualification: these counterfactual circumstances are not meant to include those that are too farfetched. $)^{7}$

Technical Preferences. The next step is to use BRIDGE as the template for a definition of an agent's 'T-preferences'. T-preference is my label for an agent's preferences in a stipulative technical sense. These are to be contrasted with an agent's preferences as understood by commonsense psychology. Here is the definition:

(DEFINE) Any given agent Eve weakly T-prefers outcome $x$ to outcome $y$ if and only if, in at least one circumstance, Eve would choose to receive $x$ guaranteed, despite the option of receiving $y$ guaranteed also being on the menu.

T-preferences are therefore defined as patterns in an agent's choices across counterfactual circumstances. Take, for example, the fact that Eve weakly T-prefers lobster to steak. This fact is, by DEFINE, the very same thing as the fact that there is some circumstance in which Eve would choose lobster when steak is on the menu.

The Shorthand Story. We are now in a position to precisely state the shorthand story, a story about economic models that assign commonsense preferences to agents. The shorthand story says that the content of such preference assignments is just the corresponding assignment of T-preferences. As I will explain in a moment, another way of putting this is:

(SHORT) Take any economist who accepts that Eve weakly prefers outcome $x$ to outcome $y$. This acceptance is just the economist's belief that Eve weakly T-prefers $x$ to $y$.

In other words, applying DEFINE: to accept this model is just for the economist to believe that in some circumstances Eve would choose to receive $x$

6. See n. 5 to see how to translate between talk of weak preferences and strict preferences.

7. A circumstance is not too farfetched, I stipulate, if the agent's commonsense preferences are the same, in that circumstance, as they actually are. (Obviously, this precludes DEFINE from offering a reductive definition of T-preferences. See extensive discussion of reductive doctrines in sec. 3.) 
guaranteed, despite the option of receiving $y$ guaranteed being on the menu. So, more generally, for an economist to accept an assignment of commonsense preferences to an agent is merely for her to believe that the agent's counterfactual choices conform to a particular pattern. ${ }^{8}$

Take any economist, for example, who models Eve as a maximizer of her commonsense preferences. One can show that, according to SHORT, the content of this model is roughly the following hypothesis called the 'weak axiom': 9

Weak Axiom: Suppose that in some circumstance Eve would choose to receive outcome $x$ (guaranteed) despite the option of receiving outcome $y$ (guaranteed) also being on the menu. And suppose that in some circumstance Eve would choose $y$ (guaranteed) from a menu also containing $x$ (guaranteed). Then there is also some circumstance in which Eve would also choose $x$ (guaranteed) from that same menu.

The Face-Value Story. This shorthand story is to be contrasted with what I call the 'face value' story. According to the face-value story, the content of the preference assignment above, for example, is just as it appears: Eve has a weak commonsense preference for lobster over steak. According to the shorthand story, in contrast, the content is that there is some circumstance in which Eve would choose lobster when steak is on the menu. But I follow most philosophers in thinking that commonsense preferences are more than such facts about an agent's counterfactual choices. (For one thing, commonsense preferences are often supposed to be the causes of such facts, not the facts themselves. ${ }^{10}$ So the face-value story and the shorthand story make contradictory claims about the content of preference assignments in economic models.

Acceptance versus Belief. An important feature of many scientific models is the gap between their face-value content and their real content. Take, for example, the equation $F=g \times \cos (\theta)$. This abstract equation can be used as a model for the motion of a ball on an inclined plane: $F$ can be construed as the net force acting on the ball down the plane, $\theta$ as the angle of the plane, and $g$ as Newton's gravitational constant. This assignment of the

8. In addition to the citations in sec. 1, refer to Friedman and Savage (1952), Binmore (2007a, 321), Bernheim and Rangel (2008), Gul and Pesendorfer (2008), Binmore (2009, 14), Gilboa $(2010,20)$, and Wakker $(2010,366)$.

9. More generally, it is the hypothesis that an agent's choices conform to the so-called strong axiom (Mas-Colell et al. 1995, chap. 1), which is a slightly bolder hypothesis than the weak axiom.

10. See Armstrong $(1968,84-85)$ and Fodor $(1968,68-71)$ for discussion. 
parts of the model to some parts of the world treats the model as saying, at face value, that the plane is perfectly frictionless and so gravity is the only force acting. So construed, I call this the face-value content of the model.

Note, however, that a physicist who accepts this model is not thereby committed to believing its face-value content. She need not believe the obvious falsehood that the plane is perfectly frictionless. This highlights the crucial and intuitive distinction between belief and acceptance: to accept a model is to be willing to use that model for various purposes, but it need not involve believing the model's face-value content. ${ }^{11}$ Instead, in virtue of accepting the model, what the physicist believes is that the frictional force is negligible (Musgrave 1981). Accordingly, let us stipulate that the real content of a model, in a given context, is the content of the beliefs that a scientist has in virtue of accepting the model in that context. This allows the face-value content of a model to come apart from the model's real content. How an economic model appears to describe the world can differ considerably from how the model itself is used to describe the world by a particular group of economists in a particular context (Morgan 2012).

How then should one characterize the role in economic models of assumptions about commonsense preferences? As I render it, the shorthand story says that the role of these assumptions is one of concision: they provide a concise shorthand in which one can formulate hypotheses about complex patterns in an agent's choices (e.g., the Weak Axiom). This role differs from the three roles of 'idealized assumptions' that have already been discussed in the literature (Musgrave 1981; Mäki 2000; Hindriks 2006). First, the real content of assignments of commonsense preferences is not that a factor in the model is negligible; contrast the factor of friction in the physicist's model. Second, the real content of assignments of commonsense preferences is not that some relationship holds but in a limited domain. Contrast, for example, the hypothesis that $F=g \times \cos (\theta)$ holds but only for frictionless planes. Third, assumptions about commonsense preferences are not required in order to make economic models mathematically tractable, that is to say, to allow economists to calculate the deductive consequences of the model's assumptions. After all, economists have developed the mathematical tools to express the theory of consumer demand, for example, solely in terms of counterfactual choices, without the need to refer to preferences of any sort (Varian 1992, chaps. 8-9). Contrast, for example, the assumption in macroeconomics that there is only one consumer in the economy, an assumption that is needed for mathematical tractability.

11. See Harman (1986, 46), Maher (1993, chap. 6), van Fraassen (1994), Kaplan (2002, 451-53), and Frankish (2004, chap. 4) for elaboration of the distinction between belief and acceptance. 
3. Theory-Independent Observation and Behaviorism. This section fends off some misplaced objections. It does so by pointing out that the shorthand story does not entail positivist doctrine 6 , nor does it entail behaviorism about commonsense psychology.

Observing Choices Independent of Theory. Positivist doctrine 6 says that there is a practical procedure for conclusively verifying or falsifying any hypothesis about any agent's choices. And this procedure does not presuppose any background theory. In particular, one can observe an agent's choices 'directly', independent of any background psychological theory, it is claimed. On this basis, one might reason as follows: "T-preferences are just patterns in an agent's choices. So hypotheses about an agent's T-preferences can be independently and conclusively tested. But the shorthand story takes the content of preference assignments in economic models to be hypotheses about T-preferences. So the shorthand story helps such economic models to be independently and conclusively tested. And this is a virtue of the shorthand story. Take, for example, a simple model in which Eve weakly prefers lobster to steak. This model is conclusively established when one comes to know that Eve chose lobster out of a menu that also contained steak."

Whatever its shortcomings, this line of thought may have been one of the original motivations behind the shorthand story in the 1930s and 1940s. In his seminal paper advocating the shorthand story, Samuelson $(1948,251)$ contends: "The whole theory of consumer's behaviour can thus be based upon operationally meaningful foundations in terms of revealed preference." And, when he talks of 'operationally meaningful foundations' here, Samuelson distinctly echoes Bridgman's (1927) infamous insistence on conclusive, theory-independent observation (Cohen 1995; Bruni and Guala 2001).

Now, in section 5, I argue that the shorthand story can be warranted entirely independently of this line of thought. For the moment, however, I merely want to register the fact that the shorthand story does not entail positivist doctrine 6 above. To see this, note that the shorthand story treats the content of preference assignments in economic models as hypotheses about choices. But it says nothing about the manner in which (and the extent to which) economists can come to know these choices. The shorthand story does not say that there is a practical procedure to conclusively identify patterns in an agent's choices and indeed to do so without presupposing any psychological theory.

This simple point is worth making because the shorthand story and positivist doctrine 6 are often treated together under the label 'the theory of revealed preference'. On the one hand, Hausman, Rosenberg, and other philosophers take revealed preference theory to mean the shorthand story: "Taken seriously, [revealed preference theory] means that talk about pref- 
erences revealed in behavior is just a useful fiction, a handy instrument. It is the most convenient description of the behavior from which all the interesting results about markets and economies follow" (Rosenberg 2008, 87). "Revealed-preference theory defines an agent's preferences in terms of what the agent would choose if the agent were able to choose" (Hausman 2012, $31)$. On the other hand, when these philosophers attack revealed preference theory, what they attack is something roughly similar to positivist doctrine 6: "the whole pretense of the behaviorists of revealed-preference theory must be surrendered. For there is no way to read my beliefs from my behavior except against some background assumptions about my preferences" (Rosenberg 2008, 88). "Economists can infer preferences from choices or choices from preferences only given premises concerning the agent's beliefs" (Hausman2012,30). (For attacks on doctrine 6 itself see the critiques of revealed preference theory in Rosenberg [1992, 123], Sen [1993, 499501, 515], Cohen [1995], and Wong [2006].)

Thus, these philosophers conflate the shorthand story with something akin to positivist doctrine 6 , a doctrine that Wong and others show to be false. And so-whether or not they intend to do so - they give the strong impression that the falsity of doctrine 6 (or kindred doctrines) is a decisive blow to the shorthand story itself. But this conclusion is premature: although the falsity of 6 removes one potential reason to favor the shorthand story, it does not decisively show that the shorthand story itself is false.

Philosophical Behaviorism. Philosophical behaviorism states that commonsense psychological facts can be characterized without using any psychological vocabulary. For example, Adrian's belief that it is raining might be characterized as the tendency of Adrian's body to move in particular ways, under various circumstances. For instance, his hand moves toward an umbrella before his body moves outdoors. Thus, the surprising behaviorist claim is that the facts of commonsense psychology are just facts about motor movements given various external circumstances - including counterfactual motor movements in counterfactual circumstances. In particular, then, commonsense preferences are just patterns among these counterfactual motor movements. But, behaviorists would add, motor movements are themselves choices. So commonsense preferences are just patterns in an agent's counterfactual choices.

In the past, the popularity of the shorthand story may have been underpinned by the popularity of philosophical behaviorism or related behaviorist doctrines: "Samuelson and others employed [the shorthand story] to get purpose and intentionality out of science. . . . For Samuelson and the behaviourists ... since purpose and intention are not observable in this sense, they have no place within science" (Hands 2004, 961). 
Now, in section 5, I argue that the shorthand story can be warranted entirely independently from behaviorism. For the moment, however, I just want to point out that the shorthand story itself does not entail behaviorism, a controversial doctrine to say the least. Thus, I take issue with Rosenberg (2008, 86), for example, who gives the strong impression to the contrary: "The implicit excuse [for keeping psychology out of economics] is founded on a self-consciously behaviorist interpretation of rational choice, the "theory of revealed preference.'" And so, since behaviorism is probably false, Rosenberg seems to suggest that the shorthand story is probably false too (88).

Does the shorthand story itself entail behaviorism, as Rosenberg seems to suggest? First, note that the shorthand story itself does not say anything about the choices to which economic models refer. On the one hand, choices may be construed in a commonsense way as intentional choice: for Eve to choose lobster (guaranteed) requires that Eve knows that her bodily movements will result in a lobster arriving or that she intend this to be the case. On the other hand, choices may be construed in a behaviorist way: for Eve to choose lobster (guaranteed) merely requires that her bodily movements will result in a lobster arriving, as a matter of actual fact. Thus, the shorthand story itself leaves open the nature of choice.

Second, consider the following analogy. Imagine a map that models the British transport network. On this map London is connected to Bristol via a blue line. And consider a story that says that the real content of such a blue line is the hypothesis that London and Bristol are linked by a motorway. Assignments of blue lines are just a shorthand, as it were, for hypotheses about motorways. Note the following obvious fact: this story does not entail that motorways are blue lines. To deny this would be to ignore the distinction between the model's face-value content and its real content. Now consider the analogous case in economics: the shorthand story says that the real content of assignments of commonsense preferences in economic models are hypotheses about an agent's T-preferences. The former is just a shorthand for the latter. But, by analogy, this story does not entail that commonsense preferences are T-preferences. In other words, the shorthand story does not entail the behaviorist doctrine that commonsense preferences are patterns of counterfactual choices. Again, this becomes clear once one distinguishes between the model's face-value content and its real content.

Conclusion. This section has fended off some misplaced objections. It has done so by pointing out that the shorthand story does not itself entail positivist doctrine 6 , which says that there is a practical, theory-independent procedure for observing agents' choices. Nor does it entail behaviorism about commonsense psychology. Given the ambiguities of their talk of 'the theory of revealed preference', Hausman and Rosenberg's treatment ob- 
scures the possibility that the shorthand story can be separated from these problematic doctrines.

4. Shielding the Status Quo from Criticism? This section will argue that the shorthand story does not issue in problematic positivist doctrines 4,5 , or 7. To keep things simple, I start with a toy example. Imagine that some researchers offer an individual - call him Conor-the choice of $x$ cans of Coke and $y$ cans of Pepsi versus $x^{*}$ cans of Coke and $y^{*}$ cans of Pepsi. And they repeat this experiment many times over the course of a year, each time varying the quantity of Coke and Pepsi on offer, $x x^{*}$ and $y y^{*}$. Imagine that these researchers discover that Conor chooses the first option over the second if and only if $(2 / 3) \ln (x)+(1 / 3) \ln (y)>(2 / 3) \ln \left(x^{*}\right)+(1 / 3) \ln \left(y^{*}\right)$. (Intuitively $(2 / 3) \ln (x)+(1 / 3) \ln (y)$ measures Conor's tendency to choose the bundle of $x$ cans of Coke and $y$ cans of Pepsi on offer.)

Suppose that these researchers find a similar pattern among the other 19 subjects in their experiment. That is to say, they find that a subject's pattern of choices can be accurately described by the function $a \ln (x)+$ $(1-a) \ln (y)$, where $a=2 / 3$ for Conor, $a=1 / 4$ for Rose, $a=1 / 2$ for Helen, and so on. The details are not important. The point is just that it looks like individuals' choices among Pepsi and Coke can be summarized by a single number $a$. The higher any individual's $a$ score, the more inclined that individual is to choose options with more Coke than Pepsi.

This is exciting news for Dr. Terzian, the chief economist at Coke: she now knows the distribution of $a$ scores among 20 experimental subjects. Applying standard statistical techniques, she can then estimate the distribution of $a$ scores among all soft drink consumers in the United States. Call this estimate the 'Terzian model'.

Of course, 20 data points is not an ideal basis on which to estimate the distribution of $a$ values among millions of soft drinks consumers. Ideally one would like a thousand data points, say. Unfortunately it is prohibitively expensive to calculate the $a$ scores of a thousand individuals using the above method, because the method requires a year-long experiment for each individual.

Imagine, however, that, during the initial experiment with 20 subjects, the experimenters discover that individuals' galvanic skin response, when drinking a can of Coke, is an excellent predictor of their $a$ score. Or alternatively one might imagine that their EEG reading when drinking a can of Coke is an excellent predictor of their $a$ score. So the researchers now have a cheaper way of improving the Terzian model: measure the galvanic skin responses or EEG responses of, say, a thousand subjects.

In summary, the content of the Terzian model is just a description of individuals' counterfactual choices. Its content includes nothing specifically 
about these individuals' psychological states. Nevertheless this model can be tested using biological and neurobiological data, such as galvanic skin responses and EEG responses. (And one can easily modify the example to illustrate how the Terzian model could be tested by cognitive data and introspective data too.) This illustrates a general point: to treat the content of an economic model as purely about choices given external circumstances does not shield the model from being undermined by cognitive, neurobiological, and introspective data, and so on - at least not completely shielded (Clarke 2014). In other words, the shorthand story does not issue in positivist doctrine 5, that the only evidence that bears on economic models is 'standard choice hypotheses': observations of agents' choices and the external circumstances under which they make them.

Once this point is clearly illustrated, it becomes obvious, one might think. Nevertheless, Craver and Alexandrova $(2008,393)$ argue against the shorthand story because they think that it "isolates economics from contributions from other disciplines." Similarly Alexandrova and Haybron (2011, sec. 2) argue against the shorthand story because "[positivist] epistemology, which eschews everything but observable behavior - and thus throws out the baby, much of our best physics, and all good sense with the bathwaterhas long since been consigned to the flames elsewhere in the academy." If I am right, then such philosophers are mistaken. Why then was this mistaken reasoning so compelling?

The first reason is this: the shorthand story does indeed shield economic theory from being undermined by some psychological data - on some occasions. Imagine a psychologist in the Coke research group who complains: "Our laboratory work shows that $a \ln (x)+(1-a) \ln (y)$ is an excellent model of individuals' choices between Coke and Pepsi, I agree. But I suggest that we start interpreting this model as a description of an individual's strength of desire for Coke and Pepsi, desire being a posit of commonsense psychology. Now, I've examined the psychological literature, and it turns out that people very rarely choose the option that they desire mostly strongly. In fact, an individual's choices are a poor guide to their desires. Thus, this psychological data from the literature casts considerable doubt on our model, as a model of desire for Coke." One might imagine that the other members of the research group respond: "No, we are going to continue to interpret the $a \ln (x)+(1-a) \ln (y)$ model as a model of choices, not as a model of desires as you insist. So your psychological data are irrelevant in this instance." On this occasion, the shorthand story does shield the model from being undermined by psychological data.

Thus, it is crucial, I suggest, to distinguish two ways in which one might try to shield a model from being undermined. The first way is to insist that there are limits on what sort of evidence can support or undermine a par- 
ticular sort of hypothesis. Call this an 'epistemological restriction'. The second way is to limit the hypotheses that form part of the real content of a model. Call this a 'content restriction'.

The Coke example highlights that the shorthand story itself is a content restriction, rather than an epistemological restriction. The shorthand story is consistent with the idea that all sorts of psychological data can support or undermine standard choice hypotheses. But the shorthand story insists that content of preference assignments in economic models are just standard choice hypotheses, not distinctively psychological hypotheses. (I wait until sec. 5 to motivate this content restriction.) It follows that psychological data that bear on the latter hypothesis, without bearing on the former, are irrelevant to testing economic models.

There is a second reason why many philosophers have mistakenly thought that the shorthand story issues in positivist doctrine 5 . This reason is rather ironic: many such philosophers seem to implicitly accept positivist doctrine 4 that hypotheses are only to be tested by their observable implications, that is to say, by noting what observations a hypothesis deductively entails and then discovering whether these predicted observations are indeed observed (Friedman 1953; Gul and Pesendorfer 2008). Now, the shorthand story says that a model's content is just a hypothesis about agents' choices given external circumstances. It follows, given 4, that 5: only data about agents' choices, and the external circumstances under which they make them, can support or undermine economic models. (This line of reasoning fails, however, because 4 is false. The Coke example illustrates this nicely: a wide range of observations can support or undermine a hypothesis, without the hypothesis deductively entailing those observations; see also Clarke 2014, sec. 4.)

Finally, there is positivist doctrine 7 , the doctrine that basic economic theory is well confirmed. To examine this doctrine, it is important to distinguish two things: it is one thing to think that a model has a particular content, and it is another thing to think that this content is true (or well confirmed). Take, for example, a philosopher who thinks that the real content of all scientific models is some hypothesis about observables (van Fraassen 1980). For example, the real content of string theoretic models is that various measuring devices in a physics laboratory will give particular readings. But let us imagine that this philosopher does not accept string theoretic models. Obviously, therefore, this philosopher is not committed to the truth of the corresponding hypothesis about these measuring devices.

Analogously, the shorthand story is committed to treating economic models as merely hypotheses about patterns in agents' choices. The real content of the model of Eve as a preference maximizer, for example, is that Eve's choices conform to the Weak Axiom (sec. 2). But, the shorthand story itself is not committed to accepting this economic model, and so it is not 
committed to the truth of the Weak Axiom. This illustrates, more generally, that the shorthand story is not committed to the claim that basic economic theory is true (or well confirmed). In other words, the shorthand story does not entail positivist doctrine 7. (Of course, one might again wonder what the point of the shorthand story could conceivably be, if not as part of a dogmatic defense of basic economic theory. I wait until sec. 5 to address this.)

This simple but important point goes unrecognized, however, because talk of the 'theory of revealed preference' in the literature conflates the shorthand story with the Weak Axiom of revealed preference. Take, for example, Reiss $(2013,35)$, who points out that agents "make all sorts of mistakes when they choose due to inattentiveness, weakness of the will, or false beliefs." And so agents' choices do not always adhere to the Weak Axiom. But the Weak Axiom is part of the content of standard economic models, when interpreted strictly according to the shorthand story (sec. 2). Therefore, Reiss points out, the content of standard economic models is false, when so interpreted. Reiss then concludes from this that "the scientific value of the technical [shorthand] concept of preference as choice is dubious" (35).

Reiss's last move is too quick. Note crucially that people are not always maximizers of their commonsense preferences. This is for exactly the reason that Reiss gives above: people "make all sorts of mistakes when they choose." It follows that the content of standard economic models is also false, when strictly treated at face value as a hypothesis about commonsense preferences. ${ }^{12}$ So Reiss's point above does not tell in favor of the face-value story over the shorthand story. It only appears to do so if one conflates the shorthand story with the Weak Axiom of revealed preference. In sum, this section has shown that the shorthand story does not itself issue in problematic positivist doctrines 4,5 , or 7 .

5. The Rationale behind the Shorthand Story. What then is the rationale behind the shorthand story, if not to provide a supposedly theoryindependent and conclusive way to evaluate economic models (sec. 3) or to shield basic economic theory from all psychological criticism (sec. 4)? To set the scene, consider the economic model of the consumer, whose facevalue content is as follows: (i) There are a range of commodities. And an agent - call him Adam - chooses how much of each of these commodities to consume. (ii) Adam has commonsense preferences over such 'commodity bundles'. In the version of the model that I want to consider, the

12. Note from sec. 2 that the face-value story applied to standard economic models is committed to BRIDGE. Note also from sec. 5 that the face-value story entails that the content of standard economic models is logically stronger than the content according to the shorthand story. 
model attributes to Adam a maximally specific assignment of preferences, $H_{P}$. These preferences are stable over time. (iii) Adam is an optimizer: he always chooses the most preferred bundle on the menu of bundles available to him. So, on this basis, the model describes which commodity bundle Adam would choose from any given menu of bundles. It describes his counterfactual choices, $H_{C}$. (iv) The menu of commodity bundles from which Adam can choose is constrained by the prices of each commodity, by Adam's income, and by the tax regime. Therefore, this description $H_{C}$ of Adam's choices specifies how price, income, and tax make a difference to Adam's choices as a consumer.

Let us imagine, however, that much of what this model says at face value about Adam's psychology is false. (a) The model describes some of Adam's commonsense preferences incorrectly. In particular, the model does not accurately describe Adam's preferences between enormous bundles, such as 1,000 loaves of bread versus 900 apples. And it does not accurately describe his preferences between minuscule bundles, such as one loaf of bread in a given month versus one apple that month. (b) Adam's commonsense preferences are not stable, as assumed, but vary somewhat depending on his mood and on environmental cues. (c) Sometimes 'interfering factors' result in Adam choosing one bundle over a second bundle, even though he has a commonsense preference for the second bundle over the first. For example, when Adam is tired or stressed he tends to make mistakes. And, suffering from a clinical pathology, on some occasions Adam compulsively buys kitchenware, rather than renting movies, for instance. This is despite the fact that Adam has a strong and stable commonsense preference for movies over kitchenware. Indeed he has no use for kitchenware, nor does it afford him any pleasure either during or after the purchase.

In spite of all this, it is perfectly possible that the model under consideration accurately describes a large proportion of Adam's counterfactual choices. Here are a few ways in which this is possible. In relation to $c$ : imagine that the model describes Adam as possessing a stronger commonsense preference for kitchenware than he in fact does possess. As a result, the model describes more or less accurately Adam's consumption of kitchenware. This slight misdescription of Adam's commonsense preferences offsets, if you like, the misdescription of Adam as a perfect optimizer of these preferences. In relation to $b$ : imagine that the model does not accurately describe Adam's commonsense preferences at any moment in time, preferences that are rather unstable. But instead the stable preferences that the model attributes to him are a good 'average' over this range of unstable preferences. As a result, the model describes more or less accurately Adam's total monthly consumption of each commodity. In relation to $a$ : imagine that Adam's income would never be low enough that only minuscule com- 
modity bundles would be on his menu of available bundles. Similarly, it would never be high enough that any enormous commodity bundles would be on the menu. As a result, the model accurately describes his choices with respect to the menus of commodity bundles that are in some sense 'practically feasible'. In this respect it does not matter that the model misdescribes Adam's commonsense preferences concerning minuscule and enormous bundles.

In summary, at face value, the above model of the consumer misdescribes much of Adam's psychology; for one thing, $H_{P}$ misdescribes Adam's commonsense preferences. Nevertheless the model's description of Adam's choices $H_{C}$ is more or less accurate - at least when considered month by month and with respect to menus that are practically feasible. But recall that $H_{C}$ is in effect a description of how price, income, and tax make a difference to Adam's choices. So the model describes these influences more or less accurately too.

Adam's case can be used to highlight the virtues of the shorthand story. Consider an economist who has two ultimate aims as far as Adam is concerned. Her first aim is to describe Adam's choices more or less accurately. Her second aim is to describe Adam's psychology more or less accurately. So the above model is very good at meeting her first aim but fails to meet her second aim. What then should this economist's attitude toward this model be? I suggest that she take an ambivalent, 'aim-relative attitude'. In the context of pursuing her aim of describing Adam's choices, she should accept the model. In the context of pursuing her aim of describing Adam's psychology, she should reject the model. This is just an extension of the idea, familiar from the modeling literature, that one's attitude toward a model will depend on one's aims (sec. 2). Incidentally, Daniel Kahneman, I think, is a great example of an economist who switches in this manner between treating economic models of decision making as models of choices, in one context, and then as models of an agent's psychology in another (Kahneman and Tversky 1979; Kahneman et al. 1997).

One can now proceed to argue as follows: $(A)$ One of the defining aims of economics is to describe how external circumstances such as price, income, and taxes make a difference to an agent's or agents' choices. But $(B)$ it is methodologically felicitous for a discipline to take an aim-relative attitude to its models. So there is a context in which it is methodologically felicitous for economics to treat preference assignments as just describing agents' choices given the external circumstances. But $(C)$ this treatment is just what the shorthand story about preference assignments (SHORT) offers. Therefore, SHORT is methodologically felicitous, where one is able to implement it coherently. But one is able to implement SHORT coherently for the overwhelming majority of preference assignments in current economic mod- 
els. ${ }^{13}$ So this shorthand story provides a methodologically felicitous treatment of such preference assignments.

I will now bolster this argument by lending further support to premise $A$ and $B$. (See sec. 2 for premise $C$.)

Premise $A$ claims that one of the defining aims of economics is to describe how external circumstances make a difference to an agent's or agents' choices, for example, the consumption of fruit in Belgium aggregated over a month. Here are some examples of the external circumstances I have in mind: the prices of each commodity in a market, the technological ability of firms to produce commodities by transforming other commodities, the initial endowment of commodities among agents and firms, and the tax regime. For example, one of the defining aims of economics is to describe how technology shocks and commodity shocks make a difference to prices, and thereby to an agent's or agents' supply and demand behavior. ${ }^{14}$ Similarly, one of the defining aims of economics is to describe how government intervention via taxation makes a difference to prices, and thereby to an agent's or agents' supply and demand behavior.

More controversially, to this list of external circumstances, one might also add the availability and distribution of information - for example, information about the quality of a commodity (secondhand cars being the classic example) or about other agents' choices (e.g., whether one's partner cooperated or defected in the last round of an iterated prisoners dilemma). Thus, one of the defining aims of so-called informational economics is to describe the way in which agents' choices are influenced by external circumstances such as indicators of quality and the choices of other agents. (Of course, a complete discussion of the content of models in information economics would also have to say something about the content of its assignments of knowledge and expectation - a task I have had to set aside for another day.)

There may of course be many other defining aims of economics. For example, one might think that it is a defining aim of economics to describe the cognitive and neurobiological mechanisms that underlie decision making (Camerer et al. 2005). Nevertheless it is clear that one of the central defining aims of economics is (also) to describe how external circumstances make a difference to an agent's or agents' choices.

13. When is one able to apply SHORT to a model without falling into logical contradiction? There are a few prerequisites. One of these is that the model takes agents to be optimizers, at face value that is. And a second is that it all permutations of outcomes constitute possible menus. Contrary to Hausman (2012), this is true of the overwhelming majority of current economic models, I claim. This article makes no claims about future economic models.

14. See Mas-Colell et al. (1995, chaps. 5C, 322) and Varian (2005, chap. 22) for some textbook examples. 
Finally and most important is premise $B$, which I put forward as a prosaic methodological guideline for model-based science. This premise says that it is methodologically felicitous for a discipline to take an aim-relative attitude to its models. To see this guideline in action, consider a climate model that, at face value, divides the globe into regions and that describes the rainfall in each region for each month in the next year. Let us say that one of the defining aims of climatology relates to tropical seasons. The aim is, namely, to describe how rainfall in the southern tropics changes from month to month. And a second aim is a cross-regional comparison. The aim is, namely, to describe how yearly rainfall varies across the various regions of the globe.

A climate model might (seem to) be very good at achieving the aim of predicting tropical seasons, for example, and (seem to) be bad at achieving the aim of cross-regional comparison. On these occasions it is methodologically felicitous for climatology to take an ambivalent, aim-relative attitude to this model. This involves treating the climate model, at one point, as a description just of seasonal changes in tropical rainfall. In this context one accepts the model. And then, at another point, one uses the model to describe just regional variance in yearly rainfall. In this second context one rejects the model. (It is important to recognize that this is not to deny that a model's ability to describe seasonal change in the tropics accurately is not sometimes strong evidence as to whether it describes cross-regional variance accurately. As I discussed in sec. 4 , the sort of evidence that bears on a hypothesis may be very broad.)

Note that premise $B$ does not say that this way of proceeding is mandatory or that it is always the best way on balance. It just says that it is one desirable way to proceed. As section 2 illustrated, it is a well-attested feature of the model-based approach to science that the same model can be used in a number of different ways (Morgan 2012). Importantly, premise $B$ is consistent with the idea that some disciplines aim to describe unobservable features of the world. This is in contrast to positivist doctrine 1. Similarly, premise $B$ is consistent with the idea that one of the defining aims of economics is to model agents' psychological states and the cognition and neurobiology of decision making. This is in contrast to positivist doctrine 2. All that premise $B$ requires is that one of the ultimate aims of economics isin addition to any aims pertaining to cognition and neurobiology - to describe how external circumstances make a difference in an agent's or agents' choices.

In summary, this section has made the warrant for the shorthand story entirely explicit. The shorthand story allows economists to focus on pursuing one of the central aims of economics, namely, describing how external circumstances make a difference to choice behavior. 
6. Conclusion. This article has examined the shorthand story about assignments of preferences in economic models (and it has put aside the wider issue of knowledge and expectation in economic models). According to the shorthand story, when an economist assigns preferences to an agent, this is for the economist to believe that the agent's choices conform to a particular pattern (sec. 2).

Section 3 preempted some misguided criticisms of the shorthand story, criticisms that Hausman, Rosenberg, and several others give the impression of endorsing. It preempted these criticisms by pointing out that the shorthand story should be distinguished from positivist doctrine 6 , which says that there is a practical, theory-independent procedure for observing an agent's choices. The shorthand story does not entail doctrine 6 , nor indeed does it entail behaviorism about commonsense psychology.

Section 4 refuted the positivist doctrine 4 that models are only to be tested by testing their observable implications. It follows - contrary to Alexandrova, Craver, and Haybron - that the shorthand story does not issue in positivist doctrine 5 , the doctrine that the only evidence that bears on economic models is observations of agents' choices and the external circumstances under which they are made. What is more - contrary to Reiss - the shorthand story itself is not committed to endorsing basic economic theory, unlike positivist doctrine 7 .

Thus, the first take-home message is this: by carefully spelling out a judicious version of the shorthand story, it becomes evident that the shorthand story does not entail positivist doctrines $4,5,6$, or 7 - despite what its critics suggest. The reason that it is so important to distinguish these problematic doctrines from the shorthand story, I contend, is that the failure to do so has prevented philosophers of economics from credibly engaging with economists. When economists see philosophers striving to criticize the shorthand story - an entirely respectable part of economic methodology - they are less likely to take seriously our criticisms of the genuinely problematic positivist doctrines.

But what is the warrant for the shorthand story? To answer this, I applied some familiar ideas from the literature on modeling. My answer was that the shorthand story allows economics to focus on one of its defining aims: to describe how external factors make a difference to choices. Thus, the shorthand story shields economic theory from being undermined by any cognitive and neurobiological data and the like that are not relevant to this aim. It shields via 'content restriction' but not by 'epistemological restriction' (sec. 4). And this restriction is warranted by the principle that it is methodologically felicitous for a discipline to take an aim-relative attitude to its models (sec. 5).

So the second take-home message is this: the shorthand story does not need to be warranted by appealing to any problematic positivist doctrines. 
In particular, one does not need to claim that (1) the defining aim of the sciences is merely to explain the observable in terms of the observable or that (2) the sole defining aim of economics is to explain choices in terms of external circumstances. Similarly, in the past, the motivation for the shorthand story may have been to provide a theory-independent and conclusive way to test economic models (sec. 3) or to shield basic economic theory from all psychological criticism (sec. 4). But this need not be its rationale today.

This addresses the concerns of critics who charge that "it is unclear what [the shorthand] reduction of preference to hypothetical choice would accomplish" (Hausman 2008, 137). It rises to the challenge posed by Alexandrova and Haybron (2011, sec. 3), who note that "what is absent is a good argument for why this is the right view of economics." And it corrects Hausman's $(2000,114)$ contention that there was "never any reason to develop [the shorthand story] in the first place. . . . There is nothing to be ashamed of in the notion of a subjective preference ranking, and it is no good pretending that economics can make do without it."

\section{REFERENCES}

Alexandrova, Anna, and Daniel M. Haybron. 2011. "High Fidelity Economics." In Elgar Companion to Recent Economic Methodology, ed. John Davis and Wade Hands, 94-120. Cheltenham: Elgar.

Armstrong, David M. 1968. A Materialist Theory of Mind. London: Routledge.

Bernheim, B. Douglas, and Antonio Rangel. 2008. "Choice-Theoretic Foundations for Behavioral Welfare Economics." In The Foundations of Positive and Normative Economics: A Handbook, ed. Andrew Caplin and Andrew Schotter, 155-92. Oxford: Oxford University Press.

Binmore, Ken. 2007a. Does Game Theory Work? The Bargaining Challenge. Cambridge, MA: MIT Press.

- 2007b. Playing for Real: A Text on Game Theory. Oxford: Oxford University Press. 2009. Rational Decisions. Princeton, NJ: Princeton University Press.

Bridgman, Percy Williams. 1927. The Logic of Modern Physics. New York: Macmillan.

Bruni, Luigino, and Francesco Guala. 2001. "Vilfredo Pareto and the Epistemological Foundations of Choice Theory." History of Political Economy 33:21-49.

Camerer, Colin F., George Loewenstein, and Drazen Prelec. 2005. "Neuroeconomics: How Neuroscience Can Inform Economics." Journal of Economic Literature 43:9-64. Revision of "Neuroeconomics: Why Economics Needs Brains." Scandinavian Journal of Economics 106 (2004): 555-79.

Clarke, Christopher. 2014. "Neuroeconomics and Confirmation Theory." Philosophy of Science 81:195-215.

Cohen, Joshua. 1995. "Samuelson's Operationalist-Descriptivist Thesis." Journal of Economic Methodology 2:53-78.

Craver, Carl, and Anna Alexandrova. 2008. "No Revolution Necessary: Neural Mechanisms for Economics." Economics and Philosophy 24:381-406.

Fodor, Jerry. 1968. Psychological Explanation: An Introduction to the Philosophy of Psychology. New York: Random House.

Frankish, Keith. 2004. Mind and Supermind. Cambridge: Cambridge University Press.

Friedman, Milton. 1953. "The Methodology of Positive Economics." In Essays in Positive Economics, 3-46. Chicago: University of Chicago Press.

Friedman, Milton, and Leonard J. Savage. 1952. "The Expected-Utility Hypothesis and the Measurability of Utility." Journal of Political Economy 60:463-74. 
Gilboa, Itzhak. 2010. Rational Choice. Cambridge, MA: MIT Press.

Gul, Faruk, and Wolfgang Pesendorfer. 2008. "The Case for Mindless Economics." In The Foundations of Positive and Normative Economics: A Handbook, ed. Andrew Caplin and Andrew Schotter, 3-39. Oxford: Oxford University Press.

Hands, D. Wade. 2004. "On Operationalisms and Economics." Journal of Economic Issues 38:953-68.

Harman, Gilbert. 1986. Change in View: Principles of Reasoning. Cambridge, MA: MIT Press.

Hausman, Daniel M. 2000. "Revealed Preference, Belief and Game Theory." Economics and Philosophy 16:99-115.

_ 2008. "Mindful or Mindless Economics: A Methodological Evaluation." In The Foundations of Positive and Normative Economics: A Handbook, ed. Andrew Caplin and Andrew Schotter, 125-53. Oxford: Oxford University Press.

. 2012. Preference, Value, Choice and Welfare. Cambridge: Cambridge University Press.

Hindriks, Frank. 2006. "Tractability Assumptions and the Musgrave-Mäki Typology.” Journal of Economic Methodology 13:401-23.

Kahneman, Daniel, and Amos Tversky. 1979. "Prospect Theory: An Analysis of Decision under Risk." Econometrica 47:263-92.

Kahneman, Daniel, Peter Wakker, and Rakesh Sarin. 1997. "Back to Bentham? Explorations of Experienced Utility." Quarterly Journal of Economics 112:375-405.

Kaplan, Mark. 2002. "Decision Theory and Epistemology." In The Oxford Handbook of Epistemology, ed. Paul K. Moser, 434-62. Oxford: Oxford University Press.

Maher, Patrick. 1993. Betting on Theories. Cambridge: Cambridge University Press.

Mäki, Uskali. 2000. "Kinds of Assumptions and Their Truth: Shaking an Untwisted F-Twist." Kyklos 53:317-35. , ed. 2002. Fact and Fiction in Economics. Cambridge: Cambridge University Press.

Mas-Colell, Andreu, Michael D. Winston, and Jerry R. Green. 1995. Microeconomic Theory. Oxford: Oxford University Press.

Morgan, Mary. 2012. The World in the Model: How Economists Work and Think. Cambridge: Cambridge University Press.

Musgrave, Alan. 1981. "Unreal Assumptions in Economic Theory: The F-Twist Untwisted." Kyklos 34:377-87.

Reiss, Julian. 2013. Philosophy of Economics: A Contemporary Introduction. Abingdon: RoutledgeTaylor.

Rosenberg, Alexander. 1992. Economics: Mathematical Politics or Science of Diminishing Returns? Chicago: University of Chicago Press.

- 2008. Philosophy of Social Science. 3rd ed. Boulder, CO: Westview.

Rubinstein, Ariel, and Yuval Salant. 2008. "Some Thoughts on the Principle of Revealed Preference." In The Foundations of Positive and Normative Economics: A Handbook, ed. Andrew Caplin and Andrew Schotter, 116-24. Oxford: Oxford University Press.

Samuelson, Paul A. 1948. "Consumption Theory in Terms of Revealed Preference." Economica $15: 243-53$

Sen, Amartya K. 1973. "Behaviour and the Concept of Preference." Economica 40:241-59. . 1993. "Internal Consistency of Choice." Econometrica 61:495-521.

van Fraassen, Bas C. 1980. The Scientific Image. Oxford: Clarendon. - 1994. "Gideon Rosen on Constructive Empiricism." Philosophical Studies 74:179-92.

Varian, Hal R. 1992. Microeconomic Analysis. 3rd ed. London: Norton. 2005. Intermediate Microeconomics: A Modern Approach. 7th ed. London: Norton.

Wakker, Peter. 2010. Prospect Theory: For Risk and Ambiguity. Cambridge: Cambridge University Press.

Wong, Stanley. 2006. The Foundations of Paul Samuelson's Revealed Preference Theory. 2nd rev. ed. London: Routledge-Taylor. 